\title{
Train English for Communication Application in English Teaching
}

\author{
Dan Zhao \\ Xijing University, Xi'an, Shaanxi, 710123, China
}

Keywords: Foreign language teaching, Communication, Use, English, Ability.

\begin{abstract}
The development of China's economy, the demand for foreign language professionals is growing, so the process of foreign language teaching in colleges and universities also pay more attention to students' use of English ability, especially oral communication skills. The current ability to use the English language has become a way to measure the effect of human learning, the teaching process in modern foreign languages, to improve students' English communication ability; we must put forward a variety of countermeasures. Based on this, this paper studies the training English for communication application in English teaching.
\end{abstract}

\section{Introduction}

Social development talent requirements are gradually upgrading, English language training and the use of English has become the main target of English teaching. Communicative competence mainly refers to students in the communication process communication and interpersonal skills, it also reflects the process of students to understand and grasp the extent of knowledge, and the degree of conversion of theoretical knowledge, the students communicative competence should focus on English listening He said write these aspects, and English teaching model is updated.

\section{Status analysis of foreign language teaching analysis}

In the current English teaching, teaching reform concept deeply rooted, traditional examination-oriented education cannot meet the teaching situation at this stage. Although teaching reform continues, but many schools are still just as reform is a form of knowledge transfer is often the center of teaching and examination-based, test teachers teach and students learn core. In the process of teaching a foreign language, many teachers teaching purpose is to allow students to get a high score, but students learn English in the sea tactical, the actual application capabilities are very lacking, which is often overlooked is the use of the ultimate goal of learning English and communication. In addition, there are many schools encourage driving on the part of English grammar to focus on teaching, whether in class or lower class time practice requires students to recite a lot of grammar, but some common syntax in the examination, in the actual spoken language used in communication the process is not common, it can be said schools and teachers spent a lot of time to allow students to learn and oral communication has little knowledge of English, so that not only enable students to master spoken English communication capability weakened, but also very easily lead to student learning attenuation of interest. In addition to teaching grammar section, many schools have a large proportion of reading in the entrance part of the University of CET, so the emphasis on reading instruction. Teachers often in order to improve student achievement, to obtain the corresponding test scores, to enable students to read a lot of articles, the consequences of this is brought about not only students learning English feel too tedious and long-term reading makes students' oral communicative competence recession, contrary to the original intention of English teaching. Integrated above the 
current status of English teaching analysis, we need to upgrade the status of oral communication in English teaching and reform the current teaching model.

\section{Principle of train students’ English ability for communication}

\section{To strengthen the students' listening training, enhance storage capacity of language}

In English teaching university, the students' knowledge of the language conversion capability requires students to acquire knowledge of the process, to grasp a lot of information, and processed self-thinking, on the basis of existing knowledge on the latest content reorganization, and impart knowledge of new content and vitality, thus achieving an effective output. Listening Practice of English Oral Communication Exercise is an important content of the listening process allows students to receive information, and information to build understanding of efforts. Listening process is divided into three phases, the first phase is to be felt, this process, students can only be rough for content identification, and a preliminary speech segment. In the second phase, the students will hear many signals to identify and establish contact with each other; the third stage is the stage of comprehension of information, through the material repeatedly listened to establish relationships with their own understanding of control between and the confidence of the control after storage in memory of them. Students in the past to speak, you need to listen to each other means, such as learners hearing oral communication links to enhance the ability of an inevitable choice.

\section{Students in English thinking habits of intensive training in English thinking ability}

Spoken English teaching focus on training students' oral communication ability, teachers teach students during the course of the oral achieve clear, smooth and meaning of the word match. Students' English habit of thinking for students learning English can play a very big role, it has also become Spoken English Training is an important content. English thinking is designed to allow students to eliminate the interference of local English language learning caused by previous, accustomed to express in English, improve their English judgment. If students have not experienced trained to think in English, then the English speaking out is bound to become a "Chinglish" cause joke, students in the learning process will translate into the English part up, carried the memory, it is likely that the language before It is expressed through the mother tongue, or directly use the expression mother tongue. This has become a troubled mother tongue English spoken by many obstacles, thoughts expressed out and cannot be proven.

\section{Hierarchical teaching methods}

Grade teaching is mainly teaching English teachers to be divided into several stages, from simple to complex, step by step, this also allows students to have a better grasp of the intensity. Specifically to analyze from the following aspects:

First of all, the first stage of learning. At this stage, teachers should strive to create a learning mood students, students are exposed to more content in English, teaching turned from abstract concrete, it is best to use some common everyday story editor dialogue into English, so that students experience the immersive feel. In addition to this, students brave expression of the mood among themselves, to master the basic types of learning English and idioms, etc., so that students in everyday English blurted talking about their feelings. Master some basic courtesy, formula language and verbal language, etc., and compensate for difficulties that may arise in the process of communication [1].

Secondly, the second phase of the study. English learning students throughout the second stage is the stage their own knowledge of the language, teaching content includes emotional life, public morality and interpersonal relationships and learning and so on topic. Teaching basic uses short narrative, depicting pictures from the beginning, it can also be a wide range of issues, and to establish the role of the story into the dialogue to interpret.

Finally, the third stage of learning. This stage belongs to a creative phase of learning, through primary and intermediate stage of the accumulation of knowledge, the students have a very strong desire for oral expression, and also mastered a certain English presentation skills, oral expression can be coherent, so for students creative expression has laid a solid foundation. At this stage, teachers teaching can give students a topic for students to a wide range of discussion and debate, such as the 
popular TV series topic, students emotional problems as well as advertising, etc. can be included in the discussion system. Way of teaching can be panel discussions and lectures and statements, and so on. Spoken in these stages can be carried out in English secondary school students, knowledge level and depth is different, after three stages of learning after students' oral communication ability to rise to a new stage [2].

\section{Countermeasures OF foreign language teaching in training as the ability to use English communication and}

\section{Information bearing language teachers of understanding}

Any language is the carrier of information, then the teachers in the teaching process to fully recognize the bearer of language information. Contains information on the effect of the language and how much information is required to pass the information itself defines value. In English, the words cannot fully express the information, the process of teaching a foreign language, oral communication is a process of exchange of information on both sides, teachers need preparation before teaching, the lesson must be taken into account to give the students what kind of information transfer, and the information to be passed out through what channels, in order to allow students to gain more and better results. If a lesson, a very large amount of information, then this lesson will be very fast-paced, and students will be like. For example, teachers teach students word in the process, the effect of using different methods obtained will be different. The traditional way is to allow students to read, and then check the teachers and teachers are further explained and exemplified, not much information in the trial process, this teaching method is included, and each will have a word and phonetic annotation, teacher message to the students passed and nothing new, so in this class will be too dull phenomenon, students lose interest in learning, the classroom was very boring. Another way is for classroom teachers carefully designed, demonstrated by the phenomenon of teaching, teachers give students to design a variety of information, including teaching methods, for example, teachers in teaching a word, to enable students to read out the correct word and recognizes letters in words and combinations of decomposition, such as, fear of the ear, is separate from another word, and there are a variety of contact era words such as, herat, bear, so appear in multiple links to the word , allows students to remember the words of explanation and words specific reading method, and a plurality of word should be able to allow students to accept.

\section{Create certain situations for students, to enhance students' ability to grasp the language}

To enable students to study the effect is more prominent, we need teachers in the teaching process to create play a teaching situation for students in a real scenario to the students a purpose for teaching, create language from real situations, real oral communication passed in dialogue and information. For example, teachers in teaching students to call, first teach students to learn some phone-related sentences, then assumed a special situation, so that students in this scenario to play freely. For example, the school should hold a speech contest tonight, so obviously students need to go home late, put this incident to call the mother. So teachers just need to specifically inform students, then let the students in their own language through the accumulation of a language practice, students meet language training function in three stages, first to understand, then practice and use, through three phases exercises, students can truly appreciate the specific case of the use of English in the context [3].

\section{Daily practice spoken English expression}

English spoken and written communication applications not only in words, in writing is also a common way. Then the teacher in the process of writing students in communicative competence to do the following:

First, according to the knowledge we learn the lesson, allowing students to take this style of writing is completed. For example, learning in college English letters, is a common colloquial expression collaboration in the letter will express their own ideas, and the use of narrative tone.

Secondly, let the students to write some of their own common things, without excessive binding on the content, and can be your own experiences learning English, how much is also not limited, as long 
as you can adhere to. What if the class or school activities, then some notice or slogan in English but also to allow students to write, student participation to them, not only can enhance students' enthusiasm for learning English, but also another way for students to understand how to learn English , English speaking and writing useful. It also can establish the contact between students and foreign students so that they understand the forms of foreign cultures as well as in the process of spoken language to communicate with each other and exchange, we can also learn from each other to communicate and network video way, help each other, constantly to enhance students' English communication and the ability to use [4].

\section{English speaking practice under the cross-cultural background}

There are great differences between the Eastern and Western culture and lifestyle, and then in English oral communication process, there will be a big difference. For example, praising a person, Asians tend to show humility, but the West will directly accept praise. There are many such differences, the process of teachers during the Oral English Teaching of students should be given constant indoctrination, no matter what the occasion, will have to penetrate into each other's cultural differences, and social customs and thinking but also on the different ways to show it. For students to create a real language environment for students to freely discuss certain topics, and then experience the fun of English oral communication, from gaining experience, confidence and the ability to upgrade.

\section{Student-centered teaching to develop spoken English training}

First, a student-centered foundation develops spoken English training for students' needs analysis. The needs of students are that students need to use a foreign language in a certain locale, and for students and characteristics, individualized, increase student learning initiative and enthusiasm. To find points of interest in the student textbook, and as a base point to start teaching, so that students in the teaching activities can truly appreciate the concept to communicate in English.

Secondly, the English two-way exchange of communication carried out. Two-way communication is the main way of dialogue, teaching activities both points the role of dialogue or conversation teaching teachers and students is a kind of two-way communication. Jingjiang teachers, students scouring more training, the ability to acquire language transmission in the repeated exercise, enhance the ability to master the language [5].

\section{Conclusion}

In summary, this article in Foreign Language Teaching and Training communicative use of English knowledge and ability to analyze research, and found the teachers in the teaching strategies used in the process to ask, hoping to play a positive teaching spoken English to help effect.

\section{References}

[1] Wang Lifei. Test report of college students' oral English communication teaching, Foreign Language Teaching and Research. 2012,34(6):426-430.

[2] Zhang Zhenghou, Lv Lei. Effect of communicative task supportive language teaching on students' oral language of non-English major-College experience English integrated course teaching reform and practice, China West Science,2011,10(26):74-75

[3] Wu Liyun. College English Oral Test guidance Communicative Language Testing on College English Teaching, Shandong Normal University, 2011.

[4] Yang Li, Han Liyang. Oral English teaching strategy, Hebei Normal University Journal (Science of education edition), 2014, 6(1):110-112.

[5] Liu Zhiwei. An Empirical Study of English Teaching of Non-English Major Students' Communicative communication apprehension and fear Regulation, Zhejiang Normal University, 2011 
